\title{
Positron annihilation spectroscopy of chain-end-functionalized polystyrenes with definite numbers of benzyl alcohol and perfluorooctyl groups
}

\author{
Kamal Reyad Mahmoud ${ }^{1 *}$ (1), Ashraf El-Shehawy ${ }^{2}$ and Hoda Atta ${ }^{1}$ \\ ${ }^{1}$ Physics Department, Faculty of Science, Kafrelsheikh University, El Gaish Street, Kafr El-Sheikh, Egypt \\ ${ }^{2}$ Chemistry Department, Faculty of Science, Kafrelsheikh University, El Gaish Street, Kafr El-Sheikh, Egypt \\ *kamalreyad@sci.kfs.edu.eg
}

\begin{abstract}
A series of well-defined chain-end-functionalized polystyrenes with a definite number of benzyl alcohol and perfluorooctyl groups $\left[\mathbf{P S}(\mathbf{B n O H})_{n} \& \mathbf{P S}(\mathbf{B n O R f})_{n}\right.$, respectively] linearly aligned in a double line at the chain-ends were prepared and investigated using XRD, SEM, PALS and DBAR spectroscopy. XRD studies showed that PS(BnOH) $)_{n}$ are crystalline and the degree of crystallinity increases with increasing the number of benzyl alcohol functionalities, while XRD pattern of PS(BnORf) revealed that incorporating perfluorooctyl groups resulting in some fractions of polystyrene chains that were intercalated or broken between the interlayer spacing. PALS measurements yielded three lifetime components and the formation probabilities as well as lifetime of ortho-positronium in polymer series were found to be dependent on the chain-end polymer structure. DBAR measurements suggested that only one type of defect is present in the polymer samples.
\end{abstract}

Keywords: benzyl alcohol and perfluorooctyl groups, hyperbranched polymers, chain-end-functionalized polystyrene, doppler broadening, free volume, positron annihilation.

How to cite: Mahmoud, K. R., El-Shehawy, A., \& Atta, H. (2019). Positron annihilation spectroscopy of chain-end-functionalized polystyrenes with definite numbers of benzyl alcohol and perfluorooctyl groups. Polimeros: Ciencia e Tecnologia, 29(4), e2019046. https://doi.org/10.1590/0104-1428.04619

\section{Introduction}

Dendrimers and hyperbranched polymers are highly branched structures of three dimensional globular macromolecules. The globular and dendritic architectures of these polymers endow them with unique structures and properties such as abundant functional groups, intramolecular cavities, low viscosity, and high solubility. The synthesis of the hyperbranched polymers and the development in their structure are of great interest due to their unique properties in a wide variety of applications. These applications not only restricted for using in medicine and pharmacy as drug delivery systems but also in solving some ecological and biological problems, as well as in modern and nano technologies ${ }^{[1-5]}$. Moreover, hyperbranched polymers have been widely applied in various fields such as light emitting materials, hybrid materials and composites, supramolecular chemistry, biomaterials, nanoscience and technology, coatings, adhesives, and modifiers. These materials have different physical, mechanical and chemical properties, which can be determined by structures of their macromolecular chains and condensed states ${ }^{[2,6-8]}$.

Positron annihilation lifetime spectroscopy (PALS) is a non destructive technique that has been used as a sensitive microprobe to study the nano scale microstructure of molecular solids. This technique is based on positron $\left(\mathrm{e}^{+}\right)$ implantation from radioactive source into the molecular solids. The positron is either annihilate with an electron of the atoms of materials or compound with an electron to form positronium (Ps) atom. Two positronium states can be formed: a single state (para-Ps, $p$-Ps) and a triplet state (ortho-Ps, $o$-Ps). Their formation probability $\left(\mathrm{I}_{\mathrm{i}}\right)$ and lifetimes $\left(\tau_{i}\right)$ can be measured, which provide information about the physical and chemical properties of such solids ${ }^{[9]}$.

The Doppler broadening (DB) of the annihilation $\gamma$-rays represents another technique related to the positron annihilation process. The DB experiments provide useful information on the contribution of the inner electronic shells and gives valuable data on chemical surrounding of the annihilation site. Two important parameters can be identified from the DB measurements are the S and W-parameters ${ }^{[10]}$. The S-parameter is defined as ratio of area under the central part of the $511 \mathrm{keV}$ line to the area under the whole annihilation line. The S-parameter characterizes the contribution of positron annihilations with the low momentum electrons, which may be present in open volume defects. Therefore, this parameter is sensitive to the average density of the open volume defects in the medium. In addition, the W-parameter can be defined as the ratio of the area under the fixed wing region of the annihilation line to the area under the whole annihilation line. This parameter is related to annihilation of positrons with deeply bound core electrons, which provides 
information about chemical environment of the defect. Several studies on polymers including hyperbranched and grafted polymers have been advantageously performed by means of the PAL technique ${ }^{[11-14]}$. The PAL technique was used to study the experimental evidence of the free volume change during the investigated processes ${ }^{[15]}$. The high sensitivity of PAS in probing free volume properties arises from the fact that the positronium atom (a positron-electron bound state) is preferentially trapped (localized) in atomic scale free volume holes located between the grain surface and the surrounding innermost polymer layer. The lifetime of positrons trapped at the grain surface defects and the grain polymer interface decreased with increasing grain size ${ }^{[16]}$.

As part of our research ${ }^{[17-21]}$ with a goal to study the nano scale microstructure of molecular solids, this study used PALS to evaluate how the number of end-functional groups affected the size and distribution of molecular level free volume in the chain-end-functionalized polystyrenes having a definite number of benzyl alcohol through systematic comparison with their corresponding polymers having the same definite number of $\mathrm{C}_{8} \mathrm{~F}_{17}$ groups. These chain-end-functionalized polystyrenes are distributed and linearly aligned in a double line at their chain-ends.

\section{Materials and Methods}

\subsection{Materials}

All chemicals ( $>98 \%$ purities) were purchased from Tokyo Kasei Co. Ltd., Japan and used as received unless otherwise noted. Tetrahydrofuran (THF) was refluxed over sodium wire for $5 \mathrm{~h}$ and then distilled over $\mathrm{LiAlH}_{4}$ under nitrogen. It was finally distilled from its sodium naphthalenide solution on the vacuum line. $N, N$-Dimethylformamide (DMF), dichloromethane, and pyridine, were distilled over $\mathrm{CaH}_{2}$ under nitrogen. 3-Perfluorooctylpropyl bromide $\left[\mathrm{C}_{8} \mathrm{~F}_{17}\left(\mathrm{CH}_{2}\right)_{3} \mathrm{Br}\right]$ was synthesized by the reaction of $\mathrm{C}_{8} \mathrm{~F}_{17}\left(\mathrm{CH}_{2}\right)_{3} \mathrm{OH}$ with carbon tetrachloride/triphenylphosphine in THF/dichloromethane according to the modified procedure previously reported ${ }^{[22]}$.

\subsection{Measurements}

${ }^{1}$ H NMR spectra were recorded on a Bruker DPX300 $(300 \mathrm{MHz})$ in $\mathrm{CDCl}_{3}$ for all polymers. Chemical shifts were recorded in ppm relative to tetramethylsilane $(\delta 0)$.

Size-exclusion chromatography (SEC) was performed on a TOSOH HLC-8020 instrument with UV (254 nm) and refractive index detection. THF was used as a carrier solvent at a flow rate of $1.0 \mathrm{~mL} / \mathrm{min}$ at $40{ }^{\circ} \mathrm{C}$. Three polystyrene gel columns (pore size (bead size)): $650 \AA(9 \mu \mathrm{m}), 200 \AA$ $(5 \mu \mathrm{m})$, and $75 \AA(5 \mu \mathrm{m}))$ were used. Measurable molecular weight ranges are $10^{3} \sim 4 \times 10^{5}(\mathrm{~g} / \mathrm{mol})$. Calibration curve was made with standard polystyrene samples for determining both $M_{n}$ and $M_{w} / M_{n}$ values.

Positron annihilation lifetime spectrometer used in this work is a fast-fast coincidence spectrometer ${ }^{[23]}$ with a resolution of $\sim 350 \mathrm{ps}$ measured using a ${ }^{60} \mathrm{Co}$ source at room temperature for the positron lifetime measurements. About $15 \mu \mathrm{Ci}$ of ${ }^{22} \mathrm{Na}$ activity was deposited and dried on a thin Kapton foils (7.6 $\mu \mathrm{m}$ thick), covered with an identical foil and were afterward glued with epoxy glue. This assembly was used as the positron source sandwiched between two identical samples. Each sample was measured at least 2-3 times differed by a total number of elementary annihilation events in the range of 1-2 million counts. The obtained spectra were analyzed using the LT computer program of Kansy ${ }^{[24]}$, with a suitable correction for the positrons annihilated in the Kapton. Three lifetime components $\left(\tau_{1}, \tau_{2}\right.$ and $\left.\tau_{3}\right)$ were obtained from the analysis of the measured spectra. The first lifetime component $\tau_{1}$ is attributed to the para-positronium (p-Ps) atom, which fixed to the value $0.125 \mathrm{~ns}$ (below the time resolution limit of the equipment). The intermediate lifetime component $\tau_{2}$ is due to the annihilation of positrons with free electrons, while the third lifetime component $\tau_{3}$ which is the longest lifetime component is related to annihilation of ortho-positronium by "pick off" mechanism in the free volume sites present in the amorphous regions. All these components were determined by the fit's variance ranged from 1.005 to 1.180 . The determination of the o-Ps components, $\tau_{3}$, provides valuable information about the mean size of free volume cavities probed by o-Ps. According to the free-volume model ${ }^{[25]}$, the lifetime of the o-Ps localized inside a rigid and spherical potential well of radius $\mathrm{R}_{0}$, and free volume of radius $\mathrm{R}$, below which no electrons are found, is given by the following expression ${ }^{[26,27]}$ :

$$
\tau_{\mathrm{o}-\mathrm{Ps}}=0.5\left[1-\left(\frac{\mathrm{R}}{\mathrm{R}_{\mathrm{o}}}\right)+(1 / 2 \pi) \operatorname{Sin}\left(\frac{2 \pi \mathrm{R}}{\mathrm{R}_{\mathrm{o}}}\right)\right]^{-1}
$$

Where $\delta R=R_{0}-R=1.656 \AA$ is the fitted empirical electron layer thickness. With this value of $\delta \mathrm{R}$, the free volume radius $\mathrm{R}$ was calculated from Equation 1 and the average size of the free volume holes $\mathrm{V}_{\mathrm{f}}$ was evaluated as $\mathrm{V}_{\mathrm{f}}=(4 / 3) \pi \mathrm{R}^{3}$ (in $\left.\AA^{3}\right)$.

Doppler broadening measurements: A p-type high-purity germanium detector (Ortec, GEM series) with an energy resolution (FWHM) of $1.6 \mathrm{keV}$ for $1.33 \mathrm{MeV}$ gamma line of ${ }^{60} \mathrm{Co}$ and relative efficiency of $25 \%$ was used to determine the Doppler broadening line-shape parameters (S and W). The amplified signals from an Ortec 570 amplifier were acquired with an Ortec 919 multichannel analyzer (MCA). A $3 \mu \mathrm{Ci}^{22} \mathrm{Na}$ source was prepared using a droplet of ${ }^{22} \mathrm{NaCl}$ solution dried onto two identical Kapton foils ( $7.5 \mu \mathrm{m}$ thick), which were afterward glued by epoxy glue. Two disk samples were arranged with the ${ }^{22} \mathrm{Na}$ source in a $4 \pi$ configuration. The energy calibration ( $68 \mathrm{eV} / \mathrm{channel})$ was achieved using the ${ }^{133} \mathrm{Ba}$ source. The Doppler broadening spectra were measured in air at room temperature. More than one million counts in the annihilation line were accumulated for each spectrum. The analysis of the obtained Doppler broadening spectra was done using SP ver. 1.0 program ${ }^{[28]}$. The centroid channel with maximum counts of the $511 \mathrm{keV}$ peak was carefully defined as it is a base for calculations of $\mathrm{S}$ - and W-parameters. The input data for this program are fixed for all spectra of the studied samples.

\subsection{Sample preparation}

The synthesized chain-end-functionalized polymers having benzyl alcohol and perfluorooctyl groups $\left[\mathbf{P S}(\mathbf{B n O H})_{\mathbf{n}}\right.$ and PS(BnORf) ${ }_{n}$, respectively] were ground and the powder was pressed into disc-shaped samples $(1 \mathrm{~cm}$ diameter and $\sim 2 \mathrm{~mm}$ thickness) using stainless steel dies. The samples were pressed at $3 \times 10^{8} \mathrm{~N} / \mathrm{m}^{2}$. To understand the crystalline 
domains and intercalation of PS between the interlayer spacing of the materials, X-ray powder diffraction data were recorded using an X-ray powder diffractometer (Shimadzu X-ray Diffractometer, XRD-6000) with CuK radiation (wavelength, $1.53 \mathrm{~A}^{\circ}$ ) source operated at $40 \mathrm{kV}$ and $30 \mathrm{~mA}$. To visualize the phase morphology and intercalated structures in the chemical compound, high resolution Scanning Electron Microscopy (SEM) (Model JSM-IT100, JEOL) was employed.

2.3.1 Synthesis of polystyrenes end-functionalized with benzyl alcohol groups $\mathrm{PS}(\mathrm{BnOH})_{N}$

A series of $\mathbf{P S}(\mathbf{B n O H})_{n}$ were readily obtained by treatment the polystyrene end-functionalized with silyl protected alcohols PS[BnOSi $\left.\left(\mathrm{CH}_{3}\right)_{2} \mathbf{C}\left(\mathrm{CH}_{3}\right)_{3}\right]_{\mathrm{n}}$, prepared by our previously reported method ${ }^{[29]}$ with a 5 -fold excess of $\left(\mathrm{C}_{4} \mathrm{H}_{9}\right)_{4} \mathrm{NF}$ in THF and the reaction mixture was stirred at $25^{\circ} \mathrm{C}$ for $12 \mathrm{~h}$. The reaction was quenched with a small amount of water and the reaction mixture was poured into $1 N \mathrm{HCl}$ to precipitate the polymer. The resulting polymers were purified by reprecipitation using THF/methanol twice and freeze-drying from their absolute benzene solutions for $24 \mathrm{~h}$ to afford the objective polymers $\mathbf{P S}(\mathbf{B n O H})_{\mathbf{n}}$ in quantitative yields. All of the benzyl alcohol-functionalized polymers showed sharp and symmetrical monomodal SEC distributions similar to those of their parent polymers. In each case, quantitative deprotection of the silyl-protecting group was confirmed by the complete disappearances of tert-butyldimethylsilyl protons (0.1 and $0.9 \mathrm{ppm})$ in ${ }^{1} \mathrm{H} \mathrm{NMR}^{[29]}$.

\subsubsection{Introduction of $\mathrm{C}_{3} \mathrm{H}_{8} \mathrm{C}_{8} \mathrm{~F}_{17}$ (Rf) groups to benzyl alcohol} functionalities of $\mathrm{PS}(\mathrm{BnOH})_{n}$ by Williamson reaction

It can be readily synthesized by the Williamson reaction of the corresponding $\mathbf{P S}(\mathbf{B n O H})_{\mathbf{n}}$ with $\mathrm{C}_{8} \mathrm{~F}_{17}\left(\mathrm{CH}_{2}\right)_{3} \mathrm{Br}$. Typical example is as follows: Under nitrogen, $\mathrm{NaH}$ (40.0 mg, $1.67 \mathrm{mmol}$ ) was added to PS(BnOH) 8 (0.204 g, $\mathrm{M}_{\mathrm{n}}=19.8 \times 103 \mathrm{~g} / \mathrm{mol}$, benzyl alcohol moiety $\left.=0.082 \mathrm{mmol}\right)$ dissolved in a mixture of THF $(10 \mathrm{~mL})$ and DMF $(3 \mathrm{~mL})$ at $0{ }^{\circ} \mathrm{C}$ and the resulting suspension was allowed to stir for $2 \mathrm{~h}$ at $25^{\circ} \mathrm{C}$. Then, $\mathrm{C}_{8} \mathrm{~F}_{17}\left(\mathrm{CH}_{2}\right)_{3} \mathrm{Br}(0.903 \mathrm{~g}, 1.67 \mathrm{mmol})$ in THF (3.00 mL) was added slowly to this suspension at $0{ }^{\circ} \mathrm{C}$ and the reaction mixture was stirred at $25^{\circ} \mathrm{C}$ for $18 \mathrm{~h}$. Water was cautiously added to quench the excess $\mathrm{NaH}$. The resulting mixture was poured into $1 N \mathrm{HCl}$ methanolic solution to precipitate the polymer. The polymer was purified by reprecipitation with $\mathrm{THF} /$ methanol twice affording PS(BnORf) ${ }_{8}(0.24 \mathrm{~g})$ in $92 \%$ yield. All other chain-end-functionalized Rf polymers were synthesized under the same conditions. All polymers were purified by reprecipitation twice, followed by freeze-drying from their benzene solutions for $24 \mathrm{~h}$. Yields of polymers isolated were usually around $90 \%$. They were characterized by ${ }^{1} \mathrm{H}$ NMR, and SEC ${ }^{[29]}$. The assignments of ${ }^{1} \mathrm{H}$ NMR spectra of these polymer series were shown below:

PS[BnOC $\left.\mathbf{H}_{3} \mathbf{C}_{8} \mathbf{F}_{17}\right]_{2}: \delta 0.5-0.7\left(\mathrm{br}, 6 \mathrm{H}, \mathrm{CH}_{3}\right), 1.2-2.4$ (br, 570H, $\mathrm{CH}_{2}$ ), 3.2-3.5 (br, 4H, $\mathrm{ArCH}_{2}$ ), 4.3-4.4 (br, 4H, $\mathrm{ArCH}_{2} \mathrm{OCH}_{2}$ ), 6.3-7.2 (br, 942H, Ar).

PS $\left[\mathrm{BnOC}_{3} \mathbf{H}_{8} \mathbf{C}_{8} \mathbf{F}_{17}\right]_{4}: \delta 0.3-0.8\left(\mathrm{br}, 12 \mathrm{H}, \mathrm{CH}_{3}\right), 1.2-2.3$ (br, 597H, $\mathrm{CH}_{2}$ ), 3.2-3.5 (br, 8H, $\mathrm{ArCH}_{2}$ ), 4.3-4.4 (br, $8 \mathrm{H}$, $\mathrm{ArCH}_{2} \mathrm{OCH}_{2}$ ), 6.3-7.2 (br, 980H, Ar).

PS[BnOC $\left.{ }_{3} \mathbf{H}_{8} \mathbf{C}_{8} \mathbf{F}_{17}\right]_{6}: \delta 0.3-0.8\left(\mathrm{br}, 6 \mathrm{H}, \mathrm{CH}_{3}\right), 1.2-2.4$ (br, 597H, $\mathrm{CH}_{2}$ ), 3.2-3.5 (br, 12H, $\mathrm{ArCH}_{2}$ ), 4.3-4.4 (br, $12 \mathrm{H}$, $\mathrm{ArCH}_{2} \mathrm{OCH}_{2}$ ), 6.3-7.3 (br, 979H, Ar).

PS[BnOC $\left.{ }_{3} \mathbf{H}_{8} \mathbf{C}_{8} \mathbf{F}_{17}\right]_{8}: \delta 0.2-0.8\left(\mathrm{br}, 12 \mathrm{H}, \mathrm{CH}_{3}\right), 1.2-2.4$ (br, 570H, $\mathrm{CH}_{2}$ ), 3.2-3.5 (br, 16H, $\mathrm{ArCH}_{2}$ ), 4.3-4.4 (br, 16H, $\mathrm{ArCH}_{2} \mathrm{OCH}_{2}$ ), 6.3-7.2 (br, 988H, Ar).

PS[BnOC $\left.{ }_{3} \mathbf{H}_{8} \mathbf{C}_{8} \mathbf{F}_{17}\right]_{10}: \delta 0.5-0.7\left(\mathrm{br}, 6 \mathrm{H}, \mathrm{CH}_{3}\right), 1.1-2.3$ (br, 761H, $\mathrm{CH}_{2}$ ), 3.1-3.5 (br, 20H, $\mathrm{ArCH}_{2}$ ), 4.2-4.5 (br, 20H, $\mathrm{ArCH}_{2} \mathrm{OCH}_{2}$ ), 6.2-7.3 (br, 1230H, Ar).

\section{Results and Discussions}

In this work, well-defined chain-end-functionalized polystyrenes with a definite number of benzyl alcohol moieties [PS( $\left.\mathbf{B n O H})_{\mathbf{n}}\right]$ linearly aligned in a double line at their chain-ends were prepared via our previously reported synthetic methodology ${ }^{[29]}$ and used as precursory polymers for introducing perfluorooctyl $\left(\mathrm{C}_{8} \mathrm{~F}_{17}\right)$ groups on their benzyl alcohol $(\mathrm{BnOH})$ functionalities, see Figure 1. They may also referred as LB-n, where " $n$ " indicates the number of either $\mathrm{BnOH}$ or $\mathrm{C}_{3} \mathrm{H}_{8} \mathrm{C}_{8} \mathrm{~F}_{17}$ groups in each polymer series.
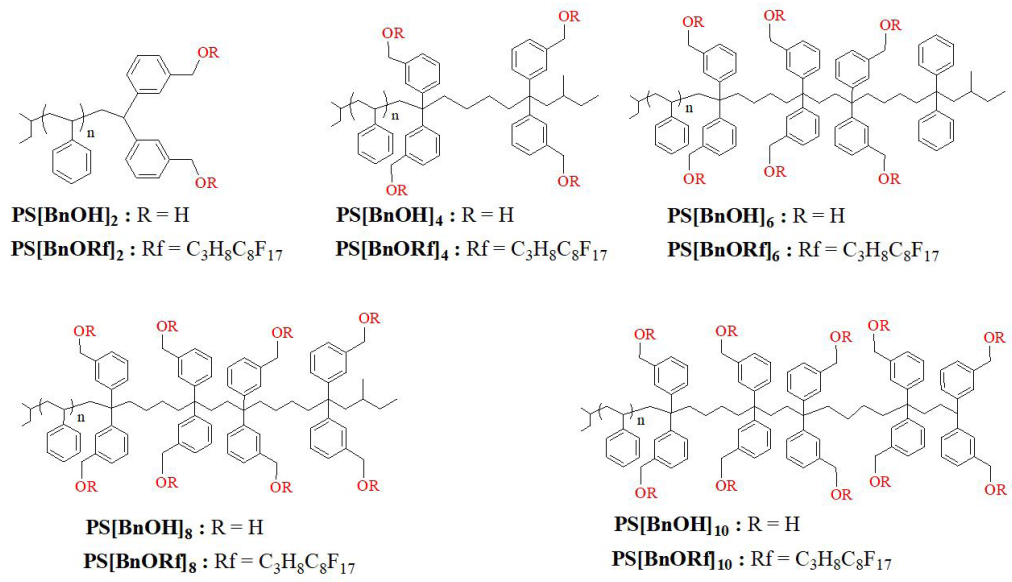

Figure 1. Structures of chain-end-functionalized polymers having benzyl alcohol and perfluorooctyl groups [PS(BnOH) $)_{n}$ and $\mathbf{P S}(\mathbf{B n O R f})_{n}$, respectively]. 
In order to prepare chain-end functionalized polystyrenes having two, four, six, eight, and ten $\mathrm{BnOH}$ functionalities, we should first prepare the corresponding precursory polymers having similar numbers of silyl-protected benzyl alcohol functionalities PS[BnOSi $\left(\mathrm{CH}_{3}\right)_{2} \mathbf{C}\left(\mathrm{CH}_{3}\right)_{3} \mathrm{I}_{\mathrm{n}}$, followed by deprotecting the $\mathrm{BnOH}$ functionalities using a 5 -fold excess of $\left(\mathrm{C}_{4} \mathrm{H}_{9}\right)_{4} \mathrm{NF}$ in THF at $25^{\circ} \mathrm{C}$ for $12 \mathrm{~h}$ to afford the desired polymers $\mathbf{P S}(\mathbf{B n O H})_{\mathbf{n}}{ }^{[29]}$. Two, four, six, eight and ten $\mathrm{C}_{8} \mathrm{~F}_{17}$ groups were then introduced at the polymer chain-ends by reacting $\mathbf{P S}(\mathbf{B n O H})_{n}(\mathrm{n}=2,4,6,8$ or 10) with $\mathrm{NaH}$, followed by treatment with $\mathrm{C}_{8} \mathrm{~F}_{17}\left(\mathrm{CH}_{2}\right)_{3} \mathrm{Br}$, a typical example is shown in Scheme 1. Thus, benzyl ether linkage was used to connect $\mathrm{C}_{3} \mathrm{H}_{8} \mathrm{C}_{8} \mathrm{~F}_{17}$ (Rf) groups to the main polystyrene chains in these polymers. They referred to as $\mathbf{P S}(\mathbf{B n O R f})_{n}(\mathrm{n}=2,4,6,8$ or 10$)$. The " $n$ " indicates the number of $\mathrm{C}_{8} \mathrm{~F}_{17}$ group in each polymer series. They referred to as PS(BnORf) and the " $n$ " indicates the number of $\mathrm{C}_{8} \mathrm{~F}_{17}$ group in each polymer series.

Fortunately, the reaction proceeded efficiently to quantitatively introduce $\mathrm{C}_{8} \mathrm{~F}_{17}$ groups. The objective $\mathrm{C}_{8} \mathrm{~F}_{17}$-chain-end-functionalized polystyrenes as well as their precursory polymers synthesized in all iteration processes possess predictable molecular weights and narrow molecular weight distributions. All analytical data are summarized in Table 1.

The $\mathrm{M}_{\mathrm{n}}$ values observed by SEC and ${ }^{1} \mathrm{H}$ NMR agreed quite well with those calculated in all cases. SEC profiles of the polymer samples exhibited symmetrical monomodal distributions and narrow molecular weight distributions were always attained. Neither shoulder nor tailing is observed in each polymer sample.

In all polymer samples, the main polystyrene chains were also designed and adjusted to be around $20 \mathrm{~kg} / \mathrm{mol}$ in $\mathrm{M}_{\mathrm{n}}$ value. Figure 2 shows SEC profiles of chain-end-functionalized polystyrenes with two, four, six, eight, and ten perfluorooctyl groups $\left(\mathrm{C}_{3} \mathrm{H}_{8} \mathrm{C}_{8} \mathrm{~F}_{17}\right.$ groups) (a-e, respectively).
As can be seen, all of these polymers exhibited sharp, symmetrical monomodal SEC distributions, indicating that all reactions proceed cleanly without any side reactions leading to chain coupling and degradation. However, small high molecular weight shoulders $(<5 \%)$, which double the molecular weight of the parent polymers, were sometimes formed during the course of the Williamson reaction. In such cases, they were completely removed by fractional precipitation using a mixture of cyclohexane and hexane.

The degrees of $\mathrm{C}_{8} \mathrm{~F}_{17}$-end-functionalization measured by ${ }^{1} \mathrm{H}$ NMR analysis were in good agreement with those expected in all cases within error limits. The molecular weights $\left(M_{n}\right.$ values) of the polymers were determined by ${ }^{1} \mathrm{H}$ NMR as follows: The molecular weight of polystyrene

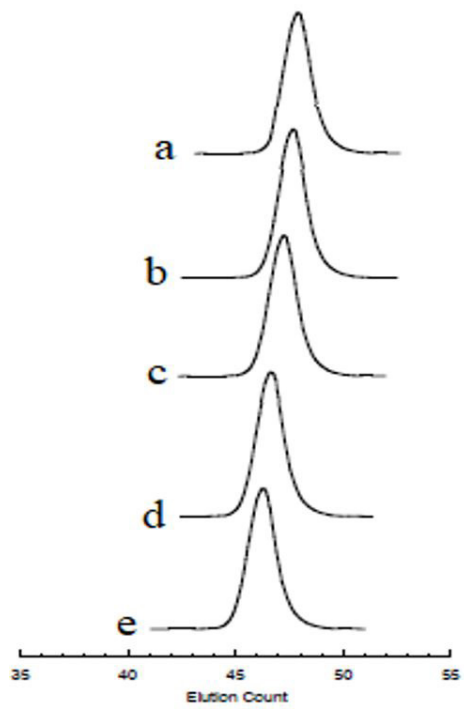

Figure 2. SEC curves for chain-end-functionalized polystyrenes with two-ten perfluorooctylpropyl ether functions (a-e, respectively).

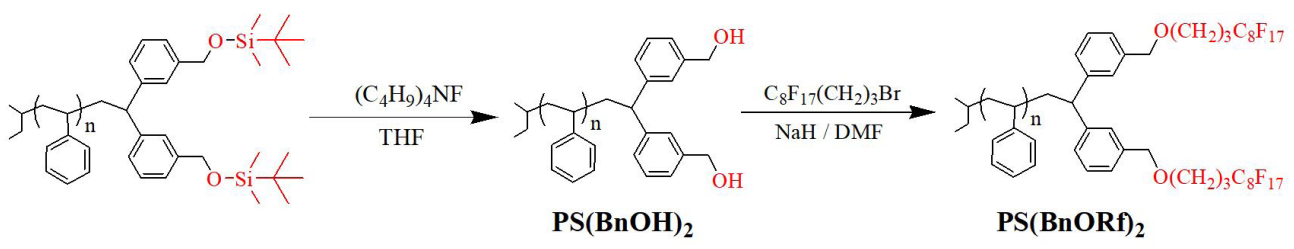

Scheme 1. Typical reaction for deprotecting the hydroxyl groups \& introducing the perfluorooctyl groups at the polymer chain-ends.

Table 1. Analytical data for the chain-end-functionalized polystyrenes with definite numbers (two, four, six, eight, and ten) benzyl alcohol and perfluorooctyl groups $\left[\mathbf{P S}(\mathbf{B n O H})_{\mathbf{n}}\right.$ and $\mathbf{P S}(\mathbf{B n O R f})_{\mathbf{n}}$, respectively].

\begin{tabular}{|c|c|c|c|c|c|c|c|c|c|c|}
\hline \multicolumn{6}{|c|}{$\mathrm{C}_{8} \mathrm{~F}_{17}$-End-Functionalized Polystyrene } & \multicolumn{5}{|c|}{ BnOH-End-Functionalized Polystyrene } \\
\hline \multirow{2}{*}{ Code } & \multicolumn{2}{|c|}{$M_{n}(\mathrm{Kg} / \mathbf{m o l})$} & \multirow{2}{*}{$\mathbf{M}_{\mathrm{w}} / \mathbf{M}_{\mathrm{n}}$} & \multicolumn{2}{|c|}{ Functionality } & \multicolumn{2}{|c|}{$M_{n}(\mathrm{Kg} / \mathbf{m o l})$} & \multirow{2}{*}{$\mathbf{M}_{\mathbf{w}} / \mathbf{M}_{\mathrm{n}}$} & \multicolumn{2}{|c|}{ Functionality } \\
\hline & Calcd $^{b}$ & Obsd $^{a}$ & & Calcd $^{b}$ & Obsd $^{a}$ & Calcd $^{\mathbf{b}}$ & Obsd $^{\mathrm{a}}$ & & Calcd $^{\text {b }}$ & Obsd $^{\mathrm{a}}$ \\
\hline LB-2 & 20.5 & 20.7 & 1.05 & 2 & 1.96 & 19.6 & 19.8 & 1.03 & 2 & 1.99 \\
\hline LB-4 & 21.4 & 22.6 & 1.03 & 4 & 3.98 & 19.6 & 20.8 & 1.04 & 4 & 3.99 \\
\hline LB-6 & 22.4 & 23.5 & 1.04 & 6 & 5.98 & 19.6 & 20.8 & 1.03 & 6 & 5.96 \\
\hline LB-8 & 23.5 & 24.7 & 1.03 & 8 & 7.99 & 19.8 & 21.1 & 1.04 & 8 & 7.96 \\
\hline LB-10 & 29.6 & 30.8 & 1.04 & 10 & 9.94 & 25.0 & 26.1 & 1.05 & 10 & 9.95 \\
\hline
\end{tabular}

${ }^{a}$ Determined by ${ }^{1} \mathrm{H}$ NMR; ${ }^{b}$ Determined by SEC. 
part was first determined by comparing ${ }^{1} \mathrm{H}$ NMR signal area ratio of aromatic protons of the main chain (6.1-7.4 ppm) with methyl protons of the initiator fragment $(0.2-0.8 \mathrm{ppm})$ (as well as SEC relative to standard polystyrene). The degree of $\mathrm{C}_{8} \mathrm{~F}_{17}$-functionalization was determined by ${ }^{1} \mathrm{H}$ NMR signal area ratio of methyl protons of the initiator fragment (0.2-0.8 ppm) to methylene protons of $\mathrm{OCH}_{2} \mathrm{CH}_{2} \mathrm{CH}_{2} \mathrm{C}_{8} \mathrm{~F}_{17}$ (3.8-4.5 ppm for ether linkage). Then, the total molecular weight of the polymer was obtained by adding the molecular weight of $\mathrm{C}_{8} \mathrm{~F}_{17}$ part to that of the polystyrene part.

Figure 3a shows XRD pattern of the chain-end functionalized polystyrenes with a definite number of benzyl alcohol groups $\mathbf{P S}(\mathbf{B n O H})_{\mathbf{n}}$ with number of branches $\mathrm{n}=2$ and $n=10$. These results provide beneficial information about the degree of crystallinity of the measured samples. The XRD pattern of benzyl alcohol group with $n=2$ shows a halo broad peak at approximately $2 \theta=18.4^{\circ}$ which may be attributed to the (100) plane due to the presence of somewhat low crystallinity and small particle size ${ }^{[30]}$. Further peaks at $2 \theta$ values of $37.7 \circ, 43 \cdot 93 \circ, 64.3$ and $77 \cdot 37 \circ$ are assigned to (111), (200), (220) and (311) crystal planes, respectively. This means that both amorphous (halo broad peak) and

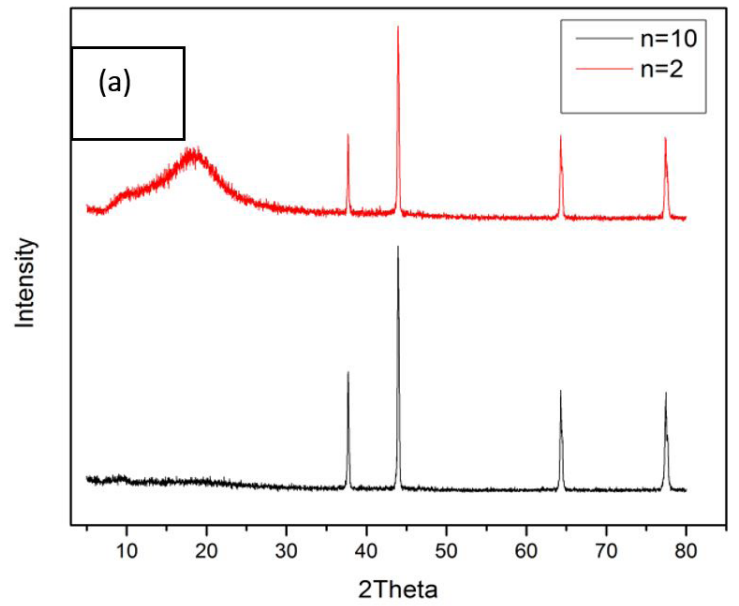

crystalline regions are found in this sample. On the other hand, as the number of branches increases to $n=10$, the amorphous halo broad peak (100) plane disappeared as shown in Figure 3a indicating that the degree of crystallinity increases with increasing branches until the material become highly crystalline.

The XRD patterns for the polystyrenes end-functionalized with perfluorooctyl groups PS(BnORf), where $n=2$ and 10 , are shown in Figure 3b. It is observed that the XRD pattern of PS(BnORf) $)_{2}$ shows five peaks at $2 \theta$ with values of $31.08,37.72,43.96,64.32$ and $77.43^{\circ}$ which correspond to $110,111,200,220$ and 311 crystal planes, respectively. On the other hand, the XRD pattern of PS(BnORf) ${ }_{10}$ shows only four peaks at $2 \theta$ values of $37.72,43.96,64.32$ and 77.43 which correspond to 111, 200, 220 and 311 miller indices, respectively. It is worth mention that the peak at $2 \theta=31.08^{\circ}$ is absent in the XRD pattern of PS(BnORf) $)_{\mathbf{1 0}}$ and this may be because some fractions of polystyrene chains were intercalated or broken between the interlayer spacing.

Figure 4 shows the representative SEM images and the typical surface morphology of $\mathbf{P S}(\mathbf{B n O H})_{n}:$ (a) $n=2$; (b) $\mathrm{n}=10$. Indeed, as revealed by SEM, a sizeable shows

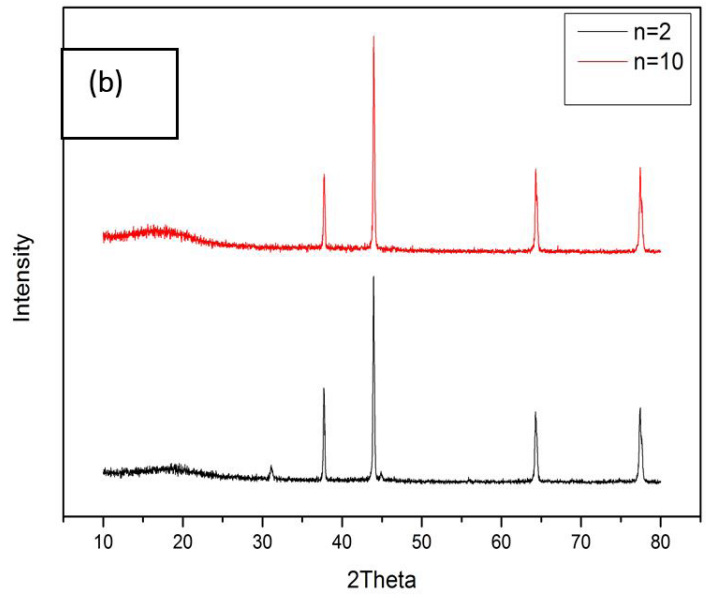

Figure 3. X-ray diffraction pattern of the chain-end-functionalized polystyrenes samples with a definite number of: (a) benzyl alcohol groups PS(BnOH)n; (b) perfluorooctyl groups PS(BnORf)n with $\mathrm{n}=2$ and $\mathrm{n}=10$.
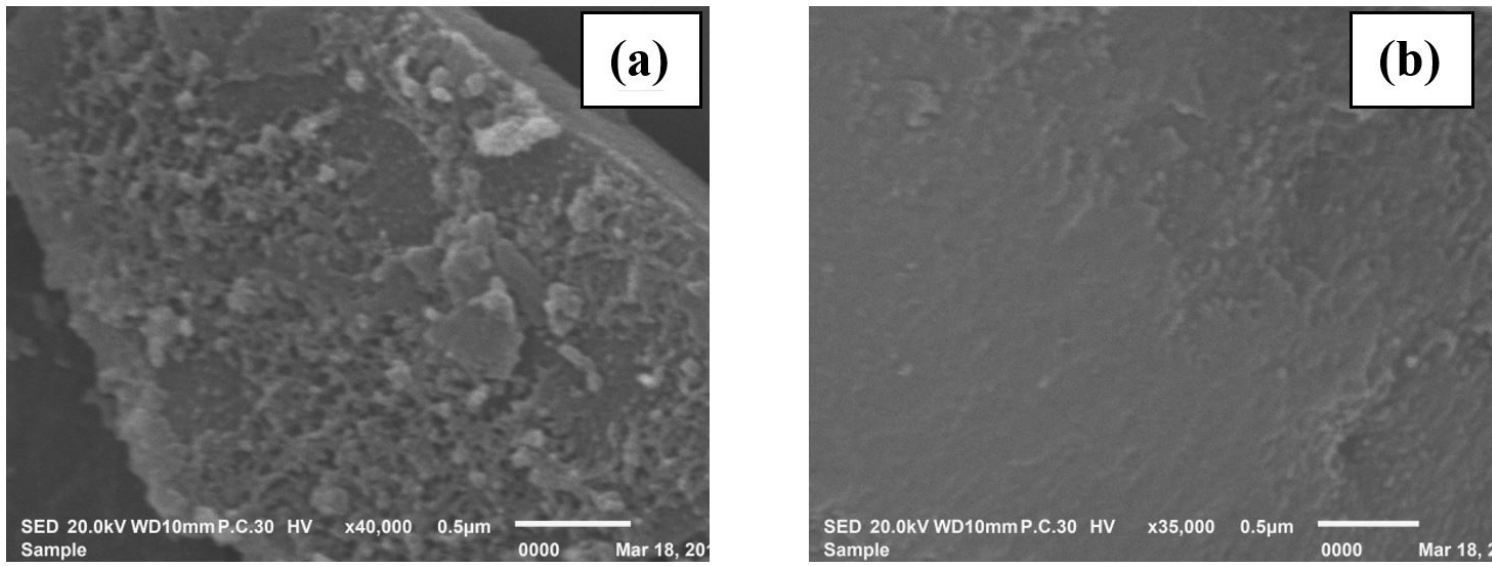

Figure 4. SEM surface micrographs of the chain-end functionalized polystyrenes with a definite number of benzyl alcohol group PS(BnOH) : (a) $n=2 ;$ (b) $n=10$. 
that roughness of the surface exists. Figure 4 shows a number of cracks and voids leading to relatively porous surface, as well as outgrowths at the junctions of the grains in the samples are apparent. However, the polymer sample with $\mathrm{n}=10$ appears in more fine structure than polymer sample with $\mathrm{n}=2$.

All polymer samples have been investigated using PALS to correlate the parameters of PAL measurements with chemical structure. All PALS spectra of the investigated polymer samples showed three lifetime components $\left(\tau_{1}, \tau_{2}\right.$ and $\left.\tau_{3}\right)$ with their respective intensities $\left(I_{1}, I_{2}\right.$ and $\left.I_{3}\right)$. The only exception was found for the sample of functionalized polymer having $10 \mathrm{Rf}$ groups which are resolved into four lifetime components $\left(\tau_{1} \tau_{2}, \tau_{3}\right.$ and $\left.\tau_{4}\right)$ with their respective intensities $\left(\mathrm{I}_{1}, \mathrm{I}_{2}, \mathrm{I}_{3}\right.$ and $\left.\mathrm{I}_{4}\right)$. These components can be attributed to various states of positron annihilation in the polymer.

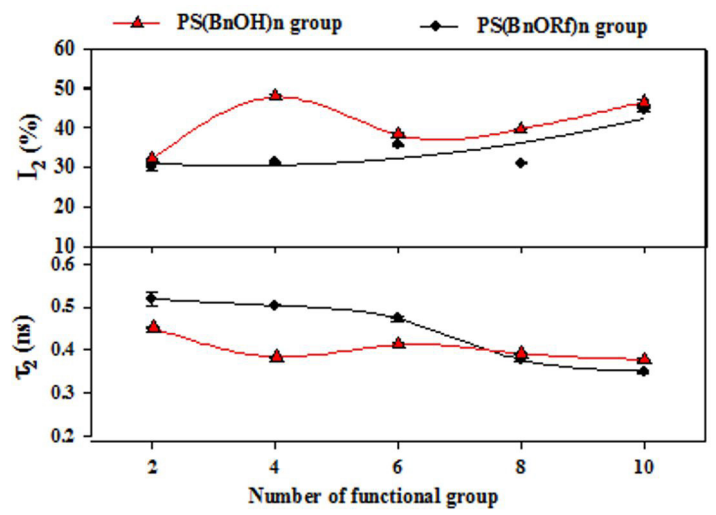

Figure 5. Variation of the lifetime $\left(\tau_{2}\right)$ and its intensity $I_{2}(\%)$ for chain-end-functionalized polymers having benzyl alcohol $\mathbf{P S}(\mathbf{B n O H})_{\mathbf{n}}$ and perfluorooctyl groups PS(BnORf) ${ }_{\mathbf{n}}$ with the number of functionalities. The solid lines are only drawn to guide the eyes.
In all cases the short-lived component, $\tau_{1}$ is attributed to para-positronium atom (p-Ps) which is especially difficult to determine precisely since its value is very sensitive to small changes in spectrometer time resolution function. In order to reduce the scatter of the other parameters extracted from the analysis, the lifetimes were analyzed with $\left(\tau_{1}\right)$ fixed at the theoretical vacuum para-Ps lifetime, $0.125 \mathrm{~ns}$. This constraint did not increase the "variance of the fit"[25].

The intermediate lifetime component $\tau_{2}$ is directly related to annihilation of the positrons without forming Ps, i.e., free positron annihilation, and $\mathrm{I}_{2}$ its intensity. Figure 5 represents the variation of the lifetime component $\tau_{2}$ and its intensity $\mathrm{I}_{2}$ with number of end-functional groups for polymer samples of $\mathbf{P S}(\mathbf{B n O H})_{\mathbf{n}}$ and $\mathbf{P S}(\mathbf{B n O R f})_{\mathbf{n}}$. The obtained results showed that $\tau_{2}$ ranged from $0.378-0.451$ and $0.348-0.501 \mathrm{~ns}$, whereas, the range of intensity $\mathrm{I}_{2}$ is $32-48 \%$ and $30.1-44.4 \%$ for the measured samples, respectively. The reduction in $\tau_{2}$ and increase of $\mathrm{I}_{2}$ can be explained by an enhancement in the electron density. A great caution must be taken when interpreting short lifetimes ${ }^{[31]}$.

The longest-lived component $\tau_{3}$ is attributed to pick-off annihilation of o-Ps localized in the open nano-spaces in the polymer structure, which are very sensitive to the microstructural changes. In this case, the o-Ps localized in a cavity or a free volume holes in polymer annihilates via the pick-off annihilation mechanism with an electron of antiparallel spin from molecules forming the cavity wall. According to the simple quantum-mechanical of Tao and Eldrop model ${ }^{[25,32]}$, the o-Ps lifetime and its intensity extracted from the lifetime spectra provide valuable information on the mean size of free volume holes where the ortho-positronium was annihilated. Figure 6 shows the lifetime $\tau_{3}$ and its intensity $\mathrm{I}_{3}$ which describe the annihilation parameters of the o-Ps in the measured polymer samples as a function of number of benzyl alcohol groups in $\mathbf{P S}(\mathbf{B n O H})_{\mathbf{n}}$ and perfluorooctyl groups in PS(BnORf) . $^{\text {. }}$

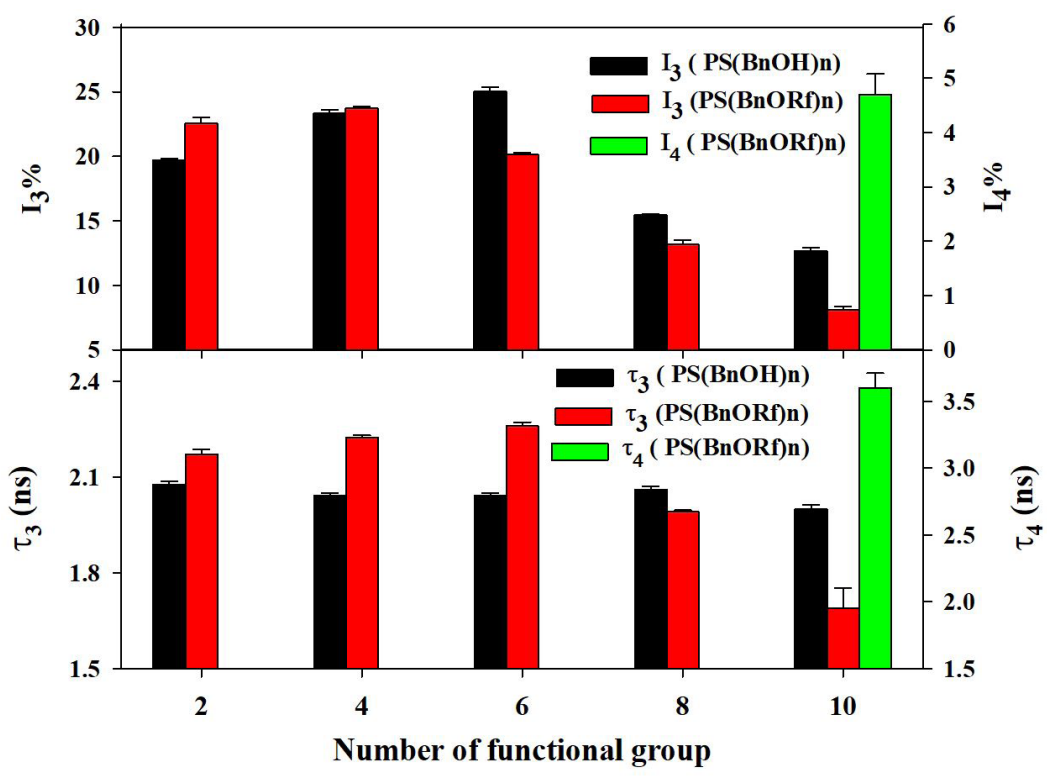

Figure 6. Variation of the lifetime $\left(\tau_{3}\right)$ and its intensity $I_{3}(\%)$ with increasing the number of benzyl alcohol and perfluorooctyl groups. The solid lines are only drawn to guide the eyes. 
The obtained results showed that $\tau_{3}$ is almost constant within one error bar with increasing the number of $\mathrm{BnOH}$ groups with a decrease in $I_{3}$ at $n=8$ and $n=10$. The enhanced reduction in $\mathrm{I}_{3}$ from $25 \%$ to $12 \%$ suggests that (o-Ps) quenching processes take place either through chemical reactions in which a complex molecule including the positron may be formed. Consequently, the positron is no longer correlated with a single electron of parallel spin resulting in reducing $\mathrm{I}_{3}$.

It has been also observed that the $\tau_{3}$ and $V_{f}$ slightly increased with increasing the number of $\mathrm{Rf}$ groups at the chain-ends up to $\mathrm{n}=6$, after that a steep decrease in $\tau_{3}$ and $\mathrm{V}_{\mathrm{f}}$ for $\mathrm{n}>6$. The increase in $\tau_{3}$ and $\mathrm{V}_{\mathrm{f}}$ can be explained according to the following features: i) The high electronegative fluorine atoms increased by increasing the number of branches in the Rf groups from 2-6 lead to the decrease of the electron density at the polymer and as a result lead to the slightly increase in $\tau_{3}$. ii) Further increasing the number of Rf groups (more than 6) resulting a steric hindrance which keep the free volume inside the polymer and hence a decrease in $\tau_{3}$ has been observed (see Figure 6). On the other hand, the variation of the average value of the relative intensity $\mathrm{I}_{3}$ with increasing the number of both $\mathrm{BnOH}$ and $\mathrm{Rf}$ groups are shown in Figure 6. The data showed that $\mathrm{I}_{3}$ increased with increasing the number of $\mathrm{BnOH}$ groups up to $\mathrm{n}=6$, then decreased with $n>6$. Increasing of $\mathrm{I}_{3}$ may be due to the presence of hydroxyl group which is a good cation scavenger that enhances Ps formation by hole scavenging when a small amount is added to the polymer ${ }^{[33]}$. The same behavior of $\mathrm{I}_{3}$ was shown for the Rf groups, where $\mathrm{I}_{3}$ slightly increased with increasing the number up to $n=4$, then steeply decreased afterwards. The decrease in $\mathrm{I}_{3}$ might be explained by the decrease in o-Ps formation probability due to decrease in the size of free volumes. The calculated values of the mean free volume, $\mathrm{V}_{\mathrm{f}}(\AA)$, as a function of the number of $\mathrm{BnOH}$ and $\mathrm{Rf}$ functionalities are shown in Figure 7. The results showed that the variation of $\mathrm{V}_{\mathrm{f}}$ with number of functional groups has the same trend as the $\tau_{3}$ (see Figure 6) and the same explanation can be suggested. As noted from Figure 7 that in $\operatorname{Ps}(\mathbf{B n O R f}), \mathrm{V}_{1}$ decreases from $122.5 \mathrm{~A}^{03}$ to $71 \mathrm{~A}^{03}$ as $\mathrm{n}$ varies from $n=6$ to $n=10$. Also, there is exist two values of the free volume $\left(\mathrm{V}_{1}\right.$ and $\left.\mathrm{V}_{2}\right)$ for the functionalized polymer having $10 \mathrm{Rf}$ groups. This is may be due to the presence of the two o-Ps lifetime values $\tau_{3}$ and $\tau_{4}$ for this polymer sample which may be attributed to the unique molecular architecture of the hyperbranched polymer, consisting of an interior cavity spaces with different sizes formed by loosely linked core and chain ends with a number of branches and functional groups. These results are in good agreements with that reported for hyperbranched poly(ether ketone) and hyperbranched-b-linear-b-hyperbranched poly(ether ketone) polymers ${ }^{[14]}$.

Although the results from positron annihilation lifetime measurements pointed to the determination of the longer lifetime component to o-Ps, it seemed interesting to confirm this conclusion using another independent technique such as Doppler Broadening of Annihilation Radiation (DBAR). The calculated values of $\mathrm{S}$ - and $\mathrm{W}$-parameters as a function of the number of $\mathrm{BnOH}$ and $\mathrm{Rf}$ groups in $\left[\mathbf{P S}(\mathbf{B n O H})_{\mathbf{n}}\right]$ and $\left[\mathbf{P S}(\mathbf{B n O R f})_{\mathbf{n}}\right]$ from the DBAR measurements are shown in Figures 8. From Figure 8A, it has been shown that the values of S-parameter decrease and $\mathrm{W}$-parameter increase with increasing the number of $\mathrm{BnOH}$ groups. This can be attributed to the decrease of the free volumes size as confermed by the PALS measurements (see Figures 6 and 7).

As for the polymers end-functionalized with $\mathrm{Rf}$ groups, the $\mathrm{S}$ - and $\mathrm{W}$-parameters increase and decrease respectively upon increase of the number of $\mathrm{Rf}$ groups from $n=2$ to $n=4$ ) Figure $8 B$. This may be due to a decrease in the valence electrons and defect size and its concentration for these compounds. In addition, the values of S- and W-parameters linearly decreased and increased respectively for polymer samples with $\mathrm{Rf}$ groups having $n>4$ which can be attributed to the increase of the fluorine atoms by increasing the number of $\mathrm{Rf}$ groups from $\mathrm{n}=4$ $\sim 10$ indicating that the annihilation with low momentum valence electrons decreased and increasing the annihilation with high momentum core electrons at the vacancies of these polymer samples.

In order to reveal some information about the number of defect types, the S-parameter can be plotted as a function of the W-parameter (S-W plots) for all the tested polymers (Figure 9). Krause-Rehberg and Leipner ${ }^{[34]}$ pointed out that for samples with only one type of defect, the plot of S versus $\mathrm{W}$ dependence should be linear. A linear behavior between the $\mathrm{S}$ and $\mathrm{W}$ - parameter is shown in Figure 9. From these plots in Figure 9, one can easily notice that, the W-parameter increases as S-parameter decreases for all tested polymer samples. In addition there is a good correlation with

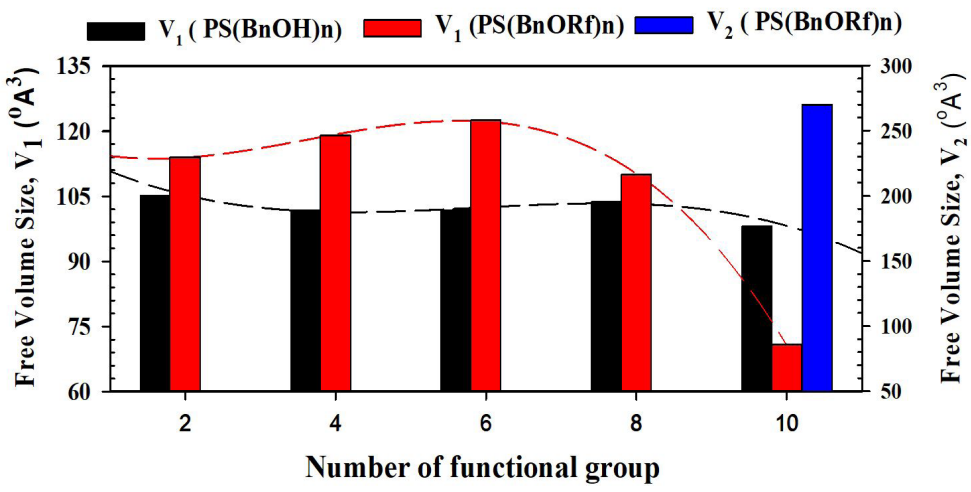

Figure 7. The calculated values of the mean free volume, $\mathrm{V}_{\mathrm{f}}(\AA)$, as a function of the number of benzyl alcohol and perfluorooctyl groups. The solid lines are only drawn to guide the eyes. 


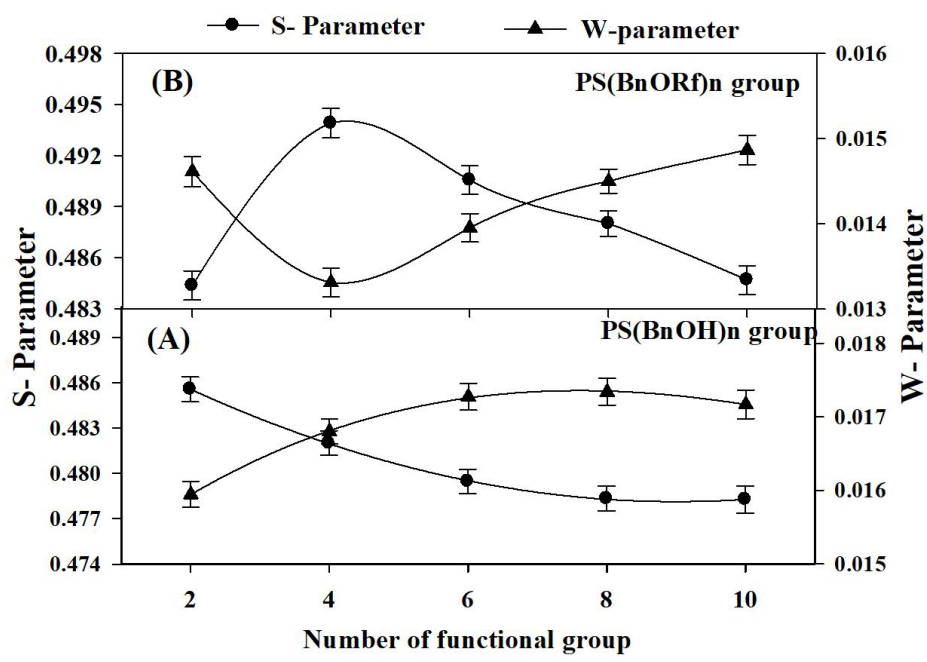

Figure 8. The variation of S- and W-parameters as a function of the number of: (A) BnOH and (B) Rf groups.
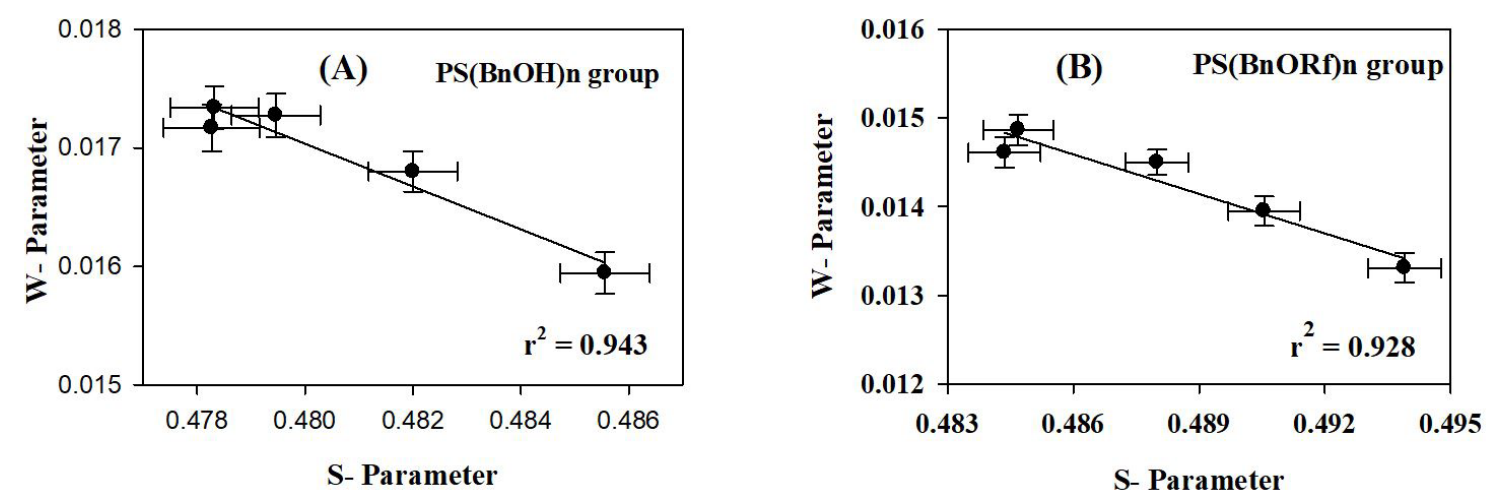

Figure 9. The S versus W plot for chain-end-functionalized polymers with different number of functional groups: (A): for BnOH groups; (B): for Rf groups.

$\mathrm{r}^{2}=0.943$ and 0.928 between S-parameter and W-parameter for polymers end-functionalized with $\mathrm{BnOH}$ and $\mathrm{R}$ f groups, respectively. These observations suggest that only one type of defect is present in these samples.

\section{Conclusions}

A series of chain-end-functionalized polystyrenes with a definite number of benzyl alcohol PS(BnOH) ${ }_{n}$ and

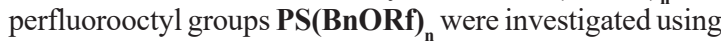
XRD, SEM, PALS and DBAR spectroscopy techniques. XRD studies showed that the polymers end-functionalized with a definite number of $\mathrm{BnOH}$ groups are crystalline and the degree of crystallinity increases by with increasing the number of $\mathrm{BnOH}$ functionalities until the polymeric material become highly crystalline by the effect of interlinking between polymer chain-ends due the possible hydrogen bonding. While, XRD pattern of polymers end-functionalized with $\mathrm{Rf}$ groups revealed that by adding branches incorporating $\mathrm{Rf}$ groups some fractions of polystyrene chains were intercalated or broken between the interlayer spacing. The surface morphology of PS(BnOH)n investigated by SEM showed that several cracks and voids leading to relatively porous surface, together with outgrowths at the junctions of the grains in the samples are apparent and the roughness of the surface exists but looks more fine structure by adding branches. Positron annihilation lifetime measurements show that formation of free volume vacancies takes place in all the investigated samples. For instance, In Ps(BnORf), $V_{1}$ decreases from $122.5 \mathrm{~A}^{03}$ to $71 \mathrm{~A}^{03}$ as $\mathrm{n}$ varies from $\mathrm{n}=6$ to $\mathrm{n}=10$. The results of Doppler broadening of annihilation radiation suggested that only one type of defect is present in these polymer samples.

\section{Reference}

1. Paleos, C. M., Tsiourvas, D., Sideratou, Z., \& Tziveleka, L.-A. (2010). Drug delivery using multifunctional dendrimers and hyperbranched polymers. Expert Opinion on Drug Delivery, 7(12), 1387-1398. http://dx.doi.org/10.1517/17425247.2010 .534981. PMid:21080860.

2. Yates, C. R., \& Hayes, W. (2004). Synthesis and applications of hyperbranched polymers. European Polymer Journal, 40(7), 1257-1281. http://dx.doi.org/10.1016/j.eurpolymj.2004.02.007.

3. Jin, H., Huang, W., Zhu, X., Zhou, Y., \& Yan, D. (2012). Biocompatible or biodegradable hyperbranched polymers: from self-assembly to cytomimetic applications. Chemical 
Society Reviews, 4l(18), 5986-5997. http://dx.doi.org/10.1039/ c2cs35130g. PMid:22797315.

4. Zheng, Y., Li, S., Weng, Z., \& Gao, C. (2015). Hyperbranched polymers: advances from synthesis to applications. Chemical Society Reviews, 44(12), 4091-4130. http://dx.doi.org/10.1039/ C4CS00528G. PMid:25902871.

5. Bruchmann, B., \& Voit, B. (2011). Applications of Hyperbranched Polymers in Coatings, as Additives, and in Nanotechnology. In: Yan D., Gao C. \& Frey H. Hyperbranched Polymers: Synthesis, properties, and applications (pp. 415-440). Hoboken, NJ: John Wiley \& Sons, Inc. http://dx.doi.org/10.1002/9780470929001. ch16.

6. Jikei, M., \& Kakimoto, M.-A. (2001). Hyperbranched aromatic polyamides prepared by direct polycondensation. High Performance Polymers, 13(2), S33-S43. http://dx.doi. org/10.1088/0954-0083/13/2/304.

7. Malmström, E., \& Hult, A. (1997). Hyperbranched polymers. Journal of Macromolecular Science, Part C., 37(3), 555-579. http://dx.doi.org/10.1080/15321799708018375.

8. Bolton, D. H., \& Wooley, K. L. (2002). Hyperbranched aryl polycarbonates derived from A2B monomers versus AB2 monomers. Journal of Polymer Science. Part A, Polymer Chemistry, 40(7), 823-835. http://dx.doi.org/10.1002/pola.10167.

9. Jean, Y. C., Mallon, P. E., \& Schrader, D. M. (2003). Principles and Applications of Positron and Positronium Chemistry. In Y. C. Jean, P. E. Mallon \& D. M. Schrader (Eds.) Introduction to positron and positronium chemistry (pp. 1-15). USA: World Scientific Publishing Co Pte Ltd. http://dx.doi.org/10.1142/9 789812775610_0001.

10. MacKenzie, I. K., Eady, J. A., \& Gingerich, R. R. (1970). The interaction between positrons and dislocations in copper and in an aluminum alloy. Physics Letters. [Part A], 33(5), 279-280. http://dx.doi.org/10.1016/0375-9601(70)90138-6.

11. López-Castañares, R., Olea-Cardoso, O., Vázquez-Moreno, F., Lizama-Soberanis, B., Camps-Carvajal, E., AngelesAnguiano, E., \& Castaño, V. (2002). Positron annihilation for characterizing polymeric materials. Bulgarian Journal of Physics, 29(3-4), 155-178.

12. Gong, W., Mai, Y., Zhou, Y., Qi, N., Wang, B., \& Yan, D. (2005). Effect of the degree of branching on atomic-scale free volume in hyperbranched poly[3-ethyl-3-(hydroxymethyl)oxetane]. A positron study. Macromolecules, 38(23), 9644-9649. http:// dx.doi.org/10.1021/ma051026j.

13. Wang, H. M., Chen, Z., Wang, P. F., \& Wang, S. J. (2009). The Influence of acrylic acid groups on the microstructure of HDPE/ PS/clay system studied by positron annihilation. Materials Science Forum, 607(3), 88-90. http://dx.doi.org/10.4028/www. scientific.net/MSF.607.88.

14. Kwak, S. Y., He, C., Suzuki, T., \& Lee, S. H. (2004). Effect of dendritic architecture on localized free volume of poly(ether ketone)s as probed by positron annihilation spectroscopy. Journal of Polymer Science. Part A, Polymer Chemistry, 42(15), 3853-3859. http://dx.doi.org/10.1002/pola.20222.

15. Ito, K., Ujihira, Y., Yamashita, T., \& Horie, K. (1999). Change in free volume during volume phase transition of $\operatorname{poly}(N$ isopropylacrylamide) gel as studied by positron annihilation lifetimes: Temperature dependence. Polymer, 40(15), 43154323. http://dx.doi.org/10.1016/S0032-3861(98)00657-0.

16. Ribeiro, E., Silva, M. E. S., Machado, J. C., Mano, V., \& Silva, G. G. (2003). Positron annihilation and differential scanning calorimetry studies of polyacrylamide and poly(dimethylacrylamide)/ poly(ethylene glycol) blends. Journal of Polymer Science. Part B, Polymer Physics, 41(13), 1493-1500. http://dx.doi. org/10.1002/polb.10490.

17. El-meniawi, M. A. H., Mahmoud, K. R., \& Megahed, M. (2016). Positron annihilation spectroscopy and mechanical properties studies for epoxy matrices reinforced with different nanoparticles. Journal of Polymer Research, 23(9), 181-192. http://dx.doi.org/10.1007/s10965-016-1074-6.

18. Mahmoud, K. R., Khodair, A. I., \& Shaban, S. Y. (2015). Positron annihilation lifetime studies of changes in free volume on some biorelevant nitrogen heterocyclic compounds and their S-glycosylation. Applied Radiation and Isotopes, 105, 303-307. http://dx.doi.org/10.1016/j.apradiso.2015.07.002. PMid:26272166.

19. Shaban, S. Y., Mahmoud, K. R., \& Sharshar, T. (2013). Positron annihilation studies of bio-related $\mathrm{N}_{2} \mathrm{~S}_{2}$-tetradentate ligands and their zinc complexes. Radiation Physics and Chemistry, 82, 12-15. http://dx.doi.org/10.1016/j.radphyschem.2012.09.001.

20. Mahmoud, K. R., Refat, M. S., Sharshar, T., Adam, A. M. A., \& Manaaa, E.-S. A. (2016). Synthesis of amino acid iodine charge transfer complexes in situ methanolic medium: chemical and physical investigations. Journal of Molecular Liquids, 222, 1061-1067. http://dx.doi.org/10.1016/j.molliq.2016.07.138.

21. Ismail, A. M., Mahmoud, K. R., \& Abd-El Salam, M. H. (2015). Electrical conductivity and positron annihilation characteristics of ternary silicone rubber/carbon black/TiB nanocomposites. Polymer Testing, 48, 37-43. http://dx.doi. org/10.1016/j.polymertesting.2015.09.006.

22. Hooz, J., \& Gilani, S. S. H. (1968). A rapid, mild procedure for the preparation of alkyl chlorides and bromides. Canadian Journal of Chemistry, 46(1), 86-87. http://dx.doi.org/10.1139/ v68-017.

23. Mahmoud, K. R., Al-Sigeny, S., Sharshar, T., \& El-Hamshary, H. (2006). Positron annihilation study on free volume of amino acid modified, starch-grafted acrylamide copolymer. Radiation Physics and Chemistry, 75(5), 590-595. http://dx.doi. org/10.1016/j.radphyschem.2005.12.037.

24. Kansy, J. (1996). Microcomputer program for analysis of positron annihilation lifetime spectra. Nuclear Instruments and Methods in Physics Research Section A: Accelerators, Spectrometers, Detectors and Associated Equipment, 374(2), 235-244. http://dx.doi.org/10.1016/0168-9002(96)00075-7.

25. Eldrup, M., Lightbody, D., \& Sherwood, J. N. (1981). The temperature dependence of positron lifetimes in solid pivalic acid. Chemical Physics, 63(1-2), 51-58. http://dx.doi. org/10.1016/0301-0104(81)80307-2.

26. McGonigle, E. A., Liggat, J. J., Pethrick, R. A., Jenkins, S. D., Daly, J. H., \& Hayward, D. (2001). Permeability of $\mathrm{N}_{2}$, $\mathrm{Ar}, \mathrm{He}, \mathrm{O}_{2}$ and $\mathrm{CO}_{2}$ through biaxially oriented polyester films - Dependence on free volume. Polymer, 42(6), 2413-2426. http://dx.doi.org/10.1016/S0032-3861(00)00615-7.

27. Porto, A. O., Silva, G. G., \& Magalha, W. F. (1999). Free volumesize dependence on temperature and average molecular-weight in poly(ethylene oxide) determined by positron annihilation lifetime spectroscopy. Journal of Polymer Science. Part B, Polymer Physics, 37, 219-226. http://dx.doi.org/10.1002/ (SICI)1099-0488(19990201)37:3<219::AID-POLB5>3.0.CO;2-I.

28. Jerzy Dryzek. (2019). Retrieved in 2019, October 18, from https://www.ifj.edu.pl/ mdryzek

29. El-Shehawy, A. A., Yokoyama, H., Sugiyama, K., \& Hirao, A. (2005). Precise synthesis of novel chain-end-functionalized polystyrenes with a definite number of perfluorooctyl groups and their surface characterization. Macromolecules, 38(20), 8285-8299. http://dx.doi.org/10.1021/ma050457z.

30. Paul, P. K., Hussain, S. A., Bhattacharjee, D., \& Pal, M. (2013). Preparation of polystyrene-clay nanocomposite by solution intercalation technique. Bulletin of Materials Science, 36(3), 361-366. http://dx.doi.org/10.1007/s12034-013-0498-4.

31. Wästlund, C., Eldrup, M., \& Maurer, F. H. J. (1998). Interlaboratory comparison of positron and positronium lifetimes in polymers. Nuclear Instruments \& Methods in Physics Research. Section 
B, Beam Interactions with Materials and Atoms, 143(4), 575583. http://dx.doi.org/10.1016/S0168-583X(98)00400-5.

32. Tao, S. J. (1972). Positronium annihilation in molecular substances. The Journal of Chemical Physics, 56(11), 54995510. http://dx.doi.org/10.1063/1.1677067.

33. Ito, Y. (1988). Vacancy Spectroscopy of polymers using positronium. In D. M. Schrader \& Y. C. Jean (Eds.), Positron and positronium chemistry (pp. 334-354). Elsevier Science: Amsterdam. https://doi.org/10.1021/bk-1998-0710.ch023.
34. Krause-Rehberg, R., \& Leipner, H. S. (1999). Positron annihilation in semiconductors: Defect Studies (Springer Series in Solid-State Sciences). Berlin: Springer-Verlag. http://dx.doi. org/10.1007/978-3-662-03893-2.

Received: July 27, 2019

Revised: Oct. 18, 2019

Accepted: Oct. 22, 2019 